Thorax (1947), 2, 176.

\title{
MEDIASTINAL CYSTS OF BRONCHIAL ORIGIN
}

BY

\author{
P. R. ALLISON
}

Leeds

[For Plates see pages 187-190]

Congenital cystic disease of the lungs has already been widely studied and described. In 1936 Schenck reviewed the literature up to that date. He says : "That pulmonary cystic disease is due to a developmental error or anomaly is now generally admitted, although many factors in the precise mechanism of its genesis are still unknown. The cyst wall may have the characteristics of bronchi, bronchioles, atria, infundibula, or alveoli. This depends at what intrauterine age the developmental error or foetal inclusion occurred." The diagnosis is usually much easier where the cysts are multiple and peripheral than when they are solitary. In each of the cases described in this paper the cyst arose from and had the structure of a large bronchus, and lay in the mediastinum between the two main bronchi behind the pericardium and in front of the oesophagus and descending aorta.

\section{CASE REPORTS}

Case 1.-A man aged 48 years was first seen in December, 1940. His main complaint had been intermittent dyspepsia for twenty years. He had had prolonged treatment for gastric ulcer. There had never been any dysphagia. During 1940 he had had two bad febrile illnesses which had been diagnosed as influenza. With each of these he had had a cough with grey sputum, vague backache, tightness across the front of the chest, a little shortness of breath, and pain in the right loin on exertion. He had lost some weight, had no appetite, and lacked energy. Clinical examination gave no lead to the diagnosis, but radiographic examination by Dr. A. Pollitt showed a large mass occupying the posterior mediastinum (Plate VII, $a$ and $b$ ). The shadow was pear-shaped, with the apex between the two main bronchi and its base nearly on the diaphragm. It projected into both sides of the chest, but mainly into the right side, where it displaced the root of the lung upwards and backwards. The mass showed no pulsation and a barium swallow was only momentarily delayed. The stomach and duodenum were normal.

A provisional diagnosis of simple mediastinal tumour was made, and an operation planned for its removal. Anaesthesia was induced with sodium pentothal and maintained with intratracheal nitrous oxide, oxygen, and cyclopropane. The right pleural cavity was opened after generous resection of parts of the seventh and eighth ribs behind. There was about $4 \mathrm{oz}$. of clear fluid in the pleural cavity but no adhesions to the chest wall, and the lung was easily displaced forwards. Soft filmy adhesions were found between the lung and the tumour, but these were easily divided without bleeding. The mass had a smooth, 
glistening silvery surface. An incision 3 in. long was made in the mediastinal pleura, and separation started along the extrapleural fascia. It was then noticed that the mass was cystic, and needle exploration showed it to contain pus-like fluid. As the nature of the infection was not known, any further mediastinal dissection was thought to be inadvisable. The cyst was therefore aspirated and well over a pint of purulent fluid removed. A tube was stitched into the cyst with a series of purse-string sutures and brought out through the chest incision. An underwater intercostal drain was placed in the pleural cavity and the chest wound closed. The lung expanded, and the pleural drain was removed after fortyeight hours. The cyst continued to drain satisfactorily, and the patient made a rapid recovery.

Examination of the fluid from the cyst showed supernatant fluid containing 3 per cent protein, the deposit consisting of caseous necrotic debris with lymphocytes, polymorphs, and red blood cells, but no bacteria. It was sterile on culture, and no tubercle bacilli were found on guinea-pig inoculation.

The patient remained in excellent health, but the tube had to be retained and drainage continued for fifteen months. He then decided to undergo a further operation for removal of the cyst.

The operation for removal was performed on April 28, 1942, under intratracheal nitrous oxide, oxygen, and ether anaesthesia. An incision was made below the drainage sinus over the ninth right rib. The lung was uniformly adherent, but separation was care. fully carried out on to the mediastinum. The pleural pocket so formed was opened into the drainage sinus above, and at this stage a little damage was caused to the indurated lung around the track. A silver catheter was passed into the cyst through the sinus and the end of the catheter palpated in the mediastinum. In this way the limits of the cyst could be identified. An incision was then made in the cyst wall extending downwards from the drainage opening, and the inside was thoroughly cleansed. Cholecystectomy forceps were applied to the cut edges, and, by firm, uniform traction with the left hand and a combination of cutting and blunt gauze dissection with the right, the walls of the cyst were ultimately separated from the surrounding structures. The anterior wall was very closely applied to the pericardium, and great caution was needed to avoid damage to this structure, but the posterior wall was freed more easily. The attachments to the bronchi were very close, but no one place was found where a communication might have existed. A little sulphanilamide powder was applied to the exposed mediastinal cellular tissues, a drainage tube inserted, and the chest wound closed. Recovery was uninterrupted, and the patient was discharged from hospital a month after operation. He is known to have remained well until December, 1943.

Dr. Horne gave the following report on the histological examination: One portion of this cyst wall is lined by a well-preserved stratified ciliated columnar epithelium (Plate VIII). Immediately outside this layer there is moderate diffuse and focal infiltration by lymphocytes and plasma cells, with marked engorgement of the capillaries. Outside this again there is a zone in which numerous mixed serous and mucous glands are present together with blocks of cartilage. One piece of cartilage shows patchy calcification. There is also a moderate amount of smooth muscle in the wall of the cyst. A second piece is lined by a discontinuous layer of flattened cells and by very old-standing granulation tissue which shows extreme engorgement of the capillaries and a moderately heavy infiltration by lymphocytes and plasma cells. The remainder of this piece consists mainly of dense fibrous tissue with only a few mixed serous and mucous glands.

Case 2.-A man aged 26 years was first seen in January, 1942. He was mentally backward. As a civilian he had been free from illness and had enjoyed working hard with pick and shovel. He joined the Army, and in June, 1941, developed pneumonia in the right 
lung. He was said to have recovered completely from this, but whilst he was at home on sick leave he began to cough up a large amount of foul sputum. This continued up to the time of his admission to the Thoracic Surgical Centre at Pinder Fields E.M.S. Hospital in January, 1942. By that time he had lost weight and complained of weakness and dizziness in addition to his cough. There was less sputum than previously but when he coughed he produced an extremely offensive smell. There were diminished movement and air entry at the right base with many moist sounds. The fingers were clubbed. Radiographs of the chest showed a cyst containing a small fluid level within the mediastinum (Plates IXa and $\mathrm{IX} b$ ). The radiograph shown in Plate $\mathrm{X} a$ was taken with greater penetration, and this shows that the cyst is placed between the two main bronchi. Plate IXa also shows much inflammatory reaction in the lower zone of the right lung. After the experience of the first case this was diagnosed with some confidence as a bronchial cyst causing pressure on the right lower lobe bronchus and secondary bronchiectasis. Bronchoscopy was performed, and this showed the larynx and trachea to be inflamed; the carina was well defined but the angle between the two main bronchi was increased. The inner wall of the right bronchus bulged into the lumen so much that this was reduced to a narrow antero-posterior slit. The bronchoscope could be passed through this into the lower lobe bronchus, and here a moderate amount of very offensive pus was aspirated. In spite of the fact that the cyst contained both liquid and gas, no bronchial communication could be found.

On Jan. 14, 1942, an attempt was made to remove the cyst. It was from fear of spreading a very severe infection in the pleural cavity that the attempt was made extrapleurally after resection of parts of the sixth and seventh ribs behind, but this came to grief as the pleura was torn before the cyst was reached. The wound was therefore closed and the pneumothorax aspirated. Some pleural infection occurred, and a small empyema. was drained.

On May 13, 1942, a second operation for removal of the cyst was done. The pleural infection had caused some rigidity of the posterior part of the chest, so that liberal portions of the sixth, seventh, and eighth ribs had to be removed in order to gain access without tearing the lung. The pleural space was obliterated by adhesions and the lung had to be separated by sharp dissection until the mediastinum behind the lung root was exposed. The cyst lay in front of the oesophagus and aorta, from which it was easily separated, and behind the pericardium, to which it was very closely attached. The cyst was opened and found to contain pus which smelled exactly the same as the patient's sputum. The contents were aspirated without spilling, and the cyst was cleaned out and packed with gauze impregnated with sulphanilamide powder. The cyst was then dissected off the pericardium and two main bronchi, but no communication with these was demonstrable. The connexion with the right main bronchus was very close, however, and knife dissection was necessary at this point. The separation of the posterior aspect was carried out easily. The mediastinal space was treated with sulphanilamide powder and a tube placed in position for drainage. Only the skin and superficial tissues were sutured. After operation bronchoscopy was performed and the obstruction of the right main bronchus was seen to be completely relieved. There was nothing to suggest that a bronchial communication had been present. Some pus was aspirated from the right lower lobe. Recovery was uneventful. Histological examination of the cyst wall proved it to have exactly the same composition as in the first case. In spite of the gross infection much of the lining retained its ciliated epithelium.

Case 3.-A man aged 46 years was admitted to hospital with signs and symptoms suggesting a bronchial carcinoma of the left lower lobe. The diagnosis was confirmed by bronchoscopy with biopsy, but during the course of this examination an orifice about $3 \mathrm{~mm}$. in diameter was noted in the lower wall of the left main bronchus about $1.5 \mathrm{~cm}$. from the carina. The edges of the orifice were well defined and showed no inflammation. A fine 
bougie could be passed into the opening for a distance of about $5 \mathrm{~mm}$., when it came to a stop. No fluid came out of the opening. When the patient died from his carcinoma a postmortem examination showed that the orifice led into a small cyst in the same position as the two previously described, and having the same histological picture (Plate $\mathrm{X} b$ ).

\section{Discussion}

Mediastinal cysts of bronchial origin are not common, but numerous examples have been described in the literature. Most often they have been found postmortem, or giving rise to bronchial obstruction in young children. Carlson (1943) described a child of 8 months who came to necropsy with such a cyst, and he brought the literature up to date at that time. In 1943 Marshall and Cookson summarized the clinical and post-mortem findings in a child of 7 months who died from respiratory obstruction caused by a cyst of bronchial origin about the size of a pigeon's egg. Adams and Thornton (1943) reported three examples, one of which was infected, and Brown and Robbins (1944) summarized the findings in twenty-one patients, twelve of whom had bronchial cysts in the mediastinum and nine in the lung. Most authors are agreed that these cysts arise in the young embryo by the separation of a diverticulum of entoderm and mesoderm from the foregut at the point at which the tracheal bud appears, or by such a separation from the growing and branching tracheal bud itself. The cysts do not usually communicate with the bronchus. They occur particularly round the bifurcation of the trachea, but may project to either side, upwards or downwards. The pressure effects on the bronchial tree depend on the exact location of the cyst. It would appear that infection of the cyst can occur without any direct bronchial communication, and if this is so it seems most likely to occur through the lymphatic vessels.

An interesting sidelight was thrown on the three cases described here by the accidental finding at necropsy of a small opening in the medial aspect of a right main bronchus just below the carina which led into a small bronchial tunnel. This emerged back again into the right lower lobe bronchus $1.5 \mathrm{in}$. below, and had all the characteristics of a bronchus. If this bronchial bud had failed to re-enter the bronchus below it would have formed a cyst comparable with that in Case 3. If it had also failed to canalize above, it would have formed a cyst comparable with Cases 1 and 2.

\section{SUMMARY}

Three examples of congenital mediastinal cyst of bronchial origin and situated at the bifurcation of the trachea are described. In the first, the cyst contained over a pint of sterile pus and did not communicate with the bronchus. In the second, the cyst contained foul-smelling pus and gas, but apparently did not communicate with the bronchus. In both, the cysts had given rise to symptoms, and both were successfully removed. In the third, a communication with the 
left main bronchus was found bronchoscopically and confirmed post mortem, the patient having died of bronchial carcinoma. This cyst was a casual finding and was apparently symptomless.

\section{REFERENCES}

Adams, W. E., and Thornton, T. F. (1943). J. thorac. Surg., 12, 503.

Brown, R. K., and Robbins, L. L. (1944). J. thorac. Surg., 13, 84.

Carlson, H. A. (1943). J. thorac. Surg., 12, 376.

Marshall, P. C., and Cookson, H. A. (1943). Lancet, 1, 305.

Schenck, S. G. (1936). Amer. J. Roentgen., 35, 604. 


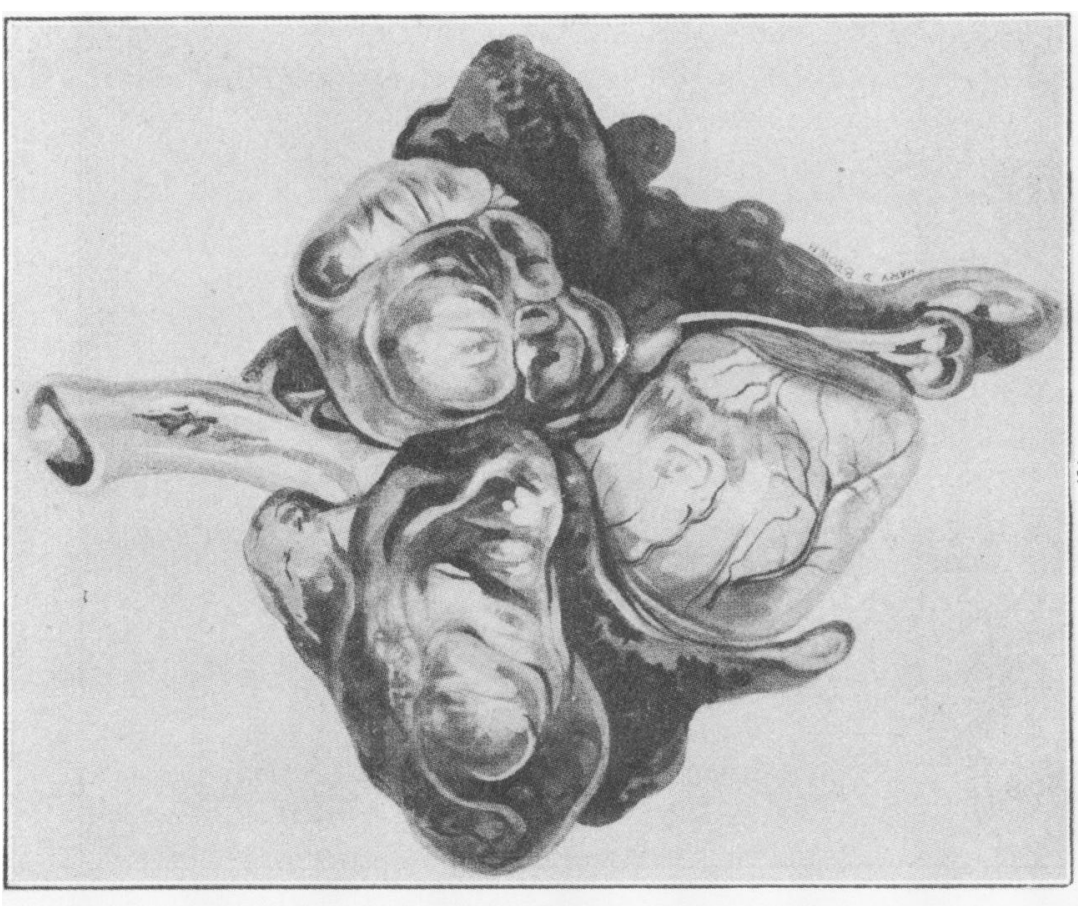

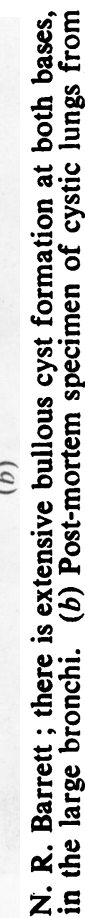

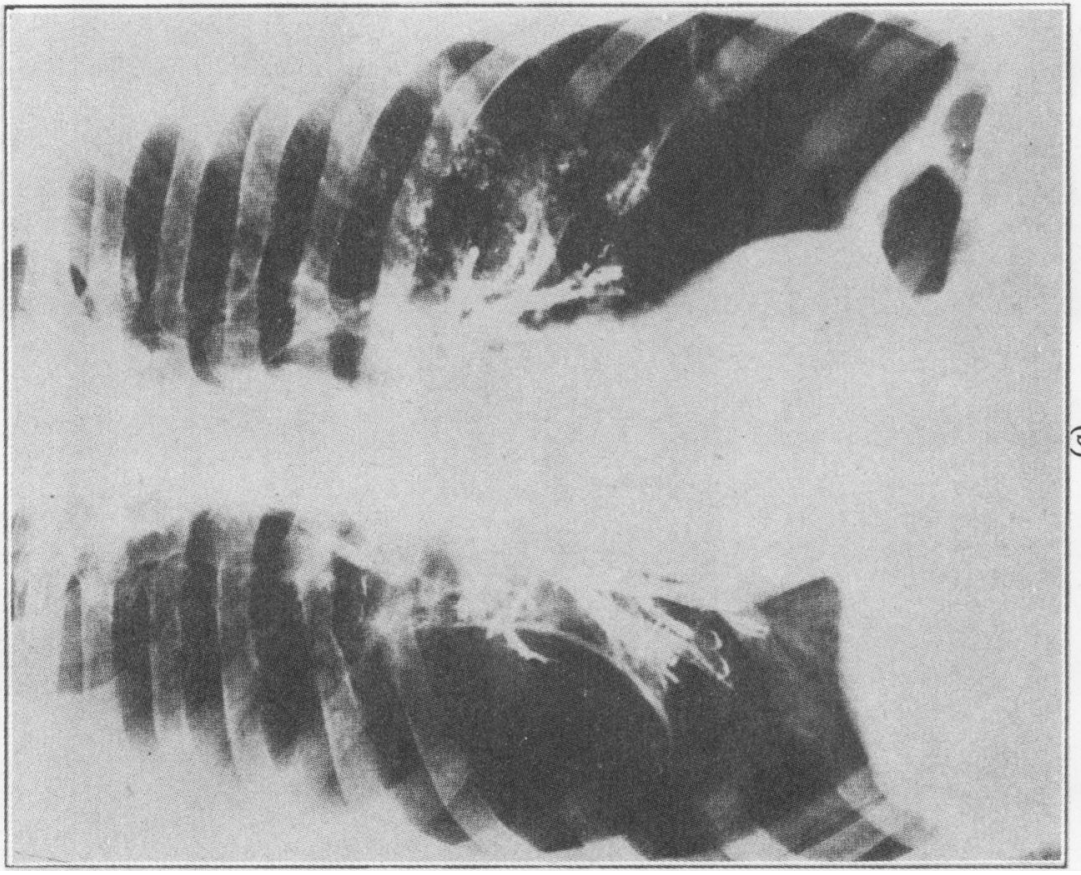

꼻융

녒

我. ن낭

फे

हुํำ

$y z$

का

总量

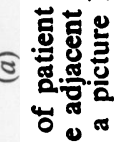

范

땡ㅇㅇㅇ

울.둔단

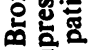

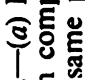

类要

蛿 

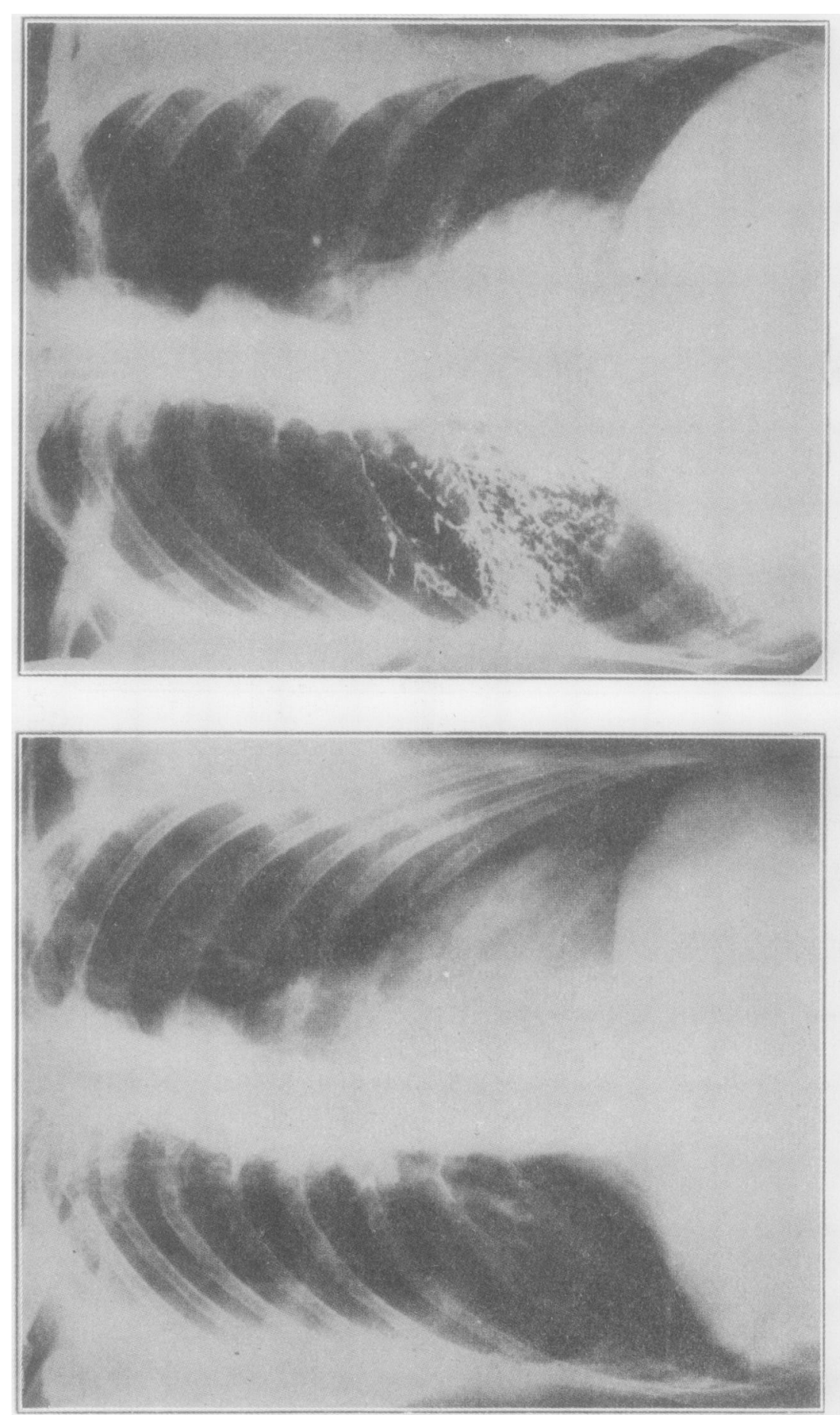

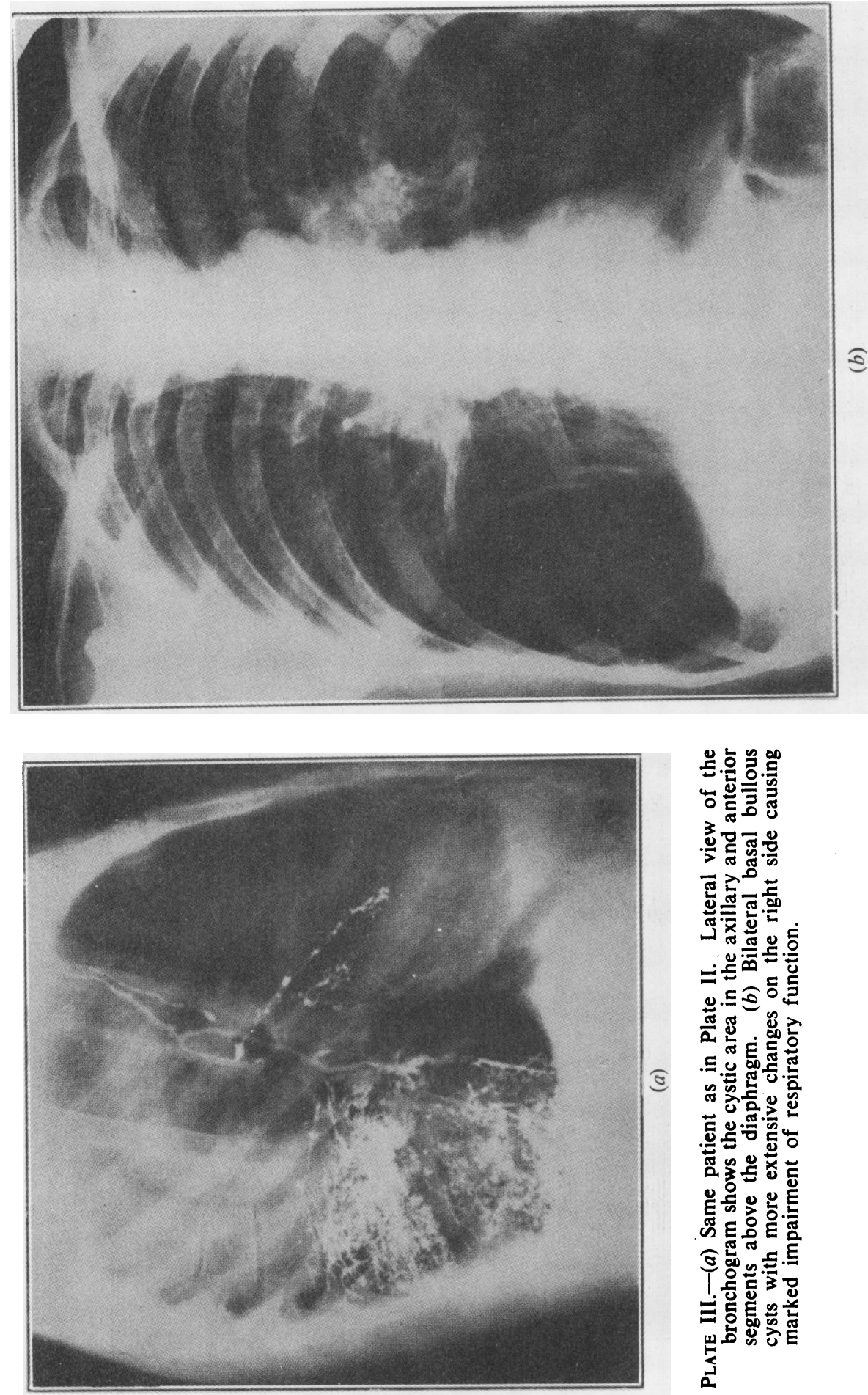

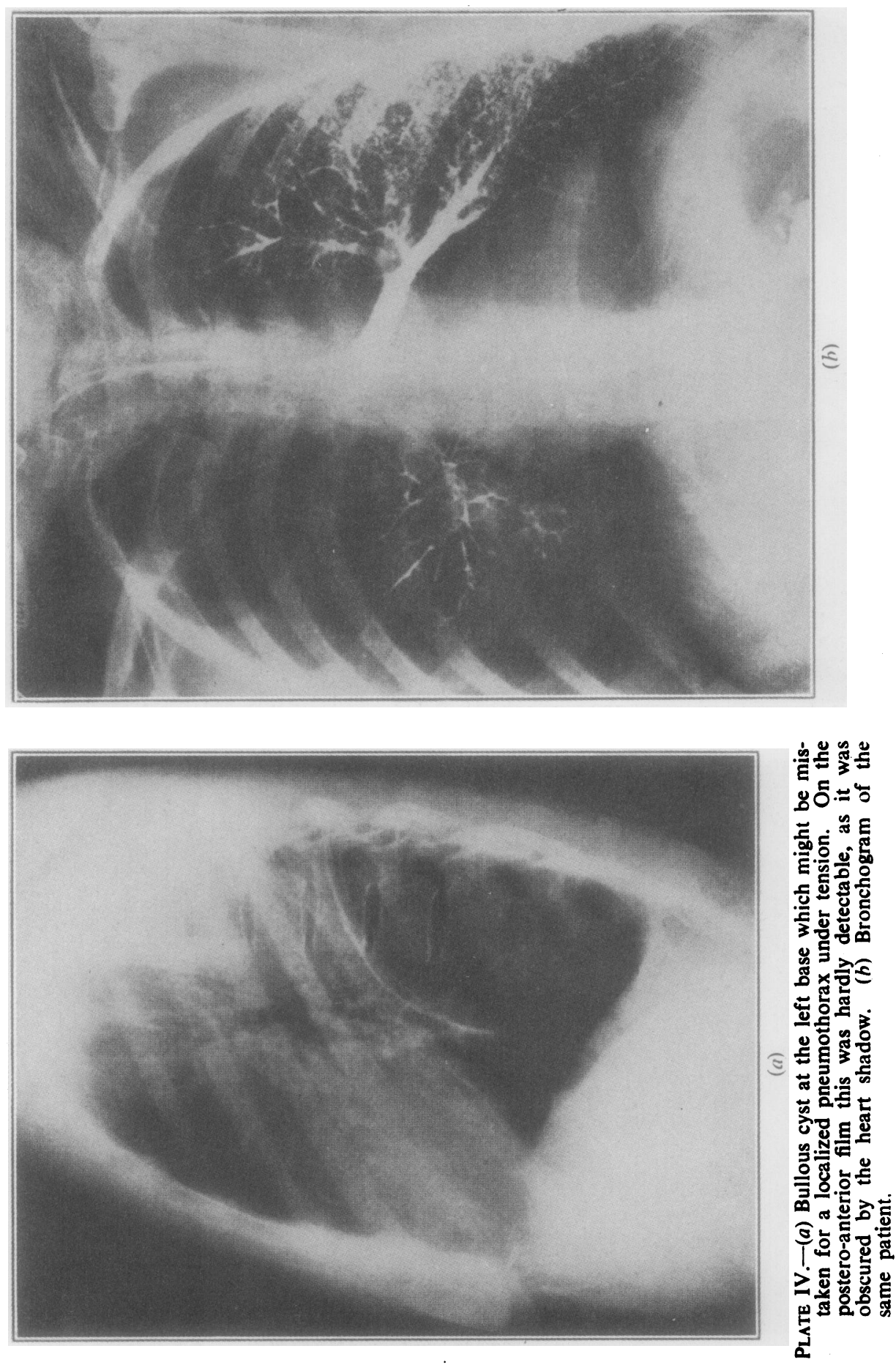

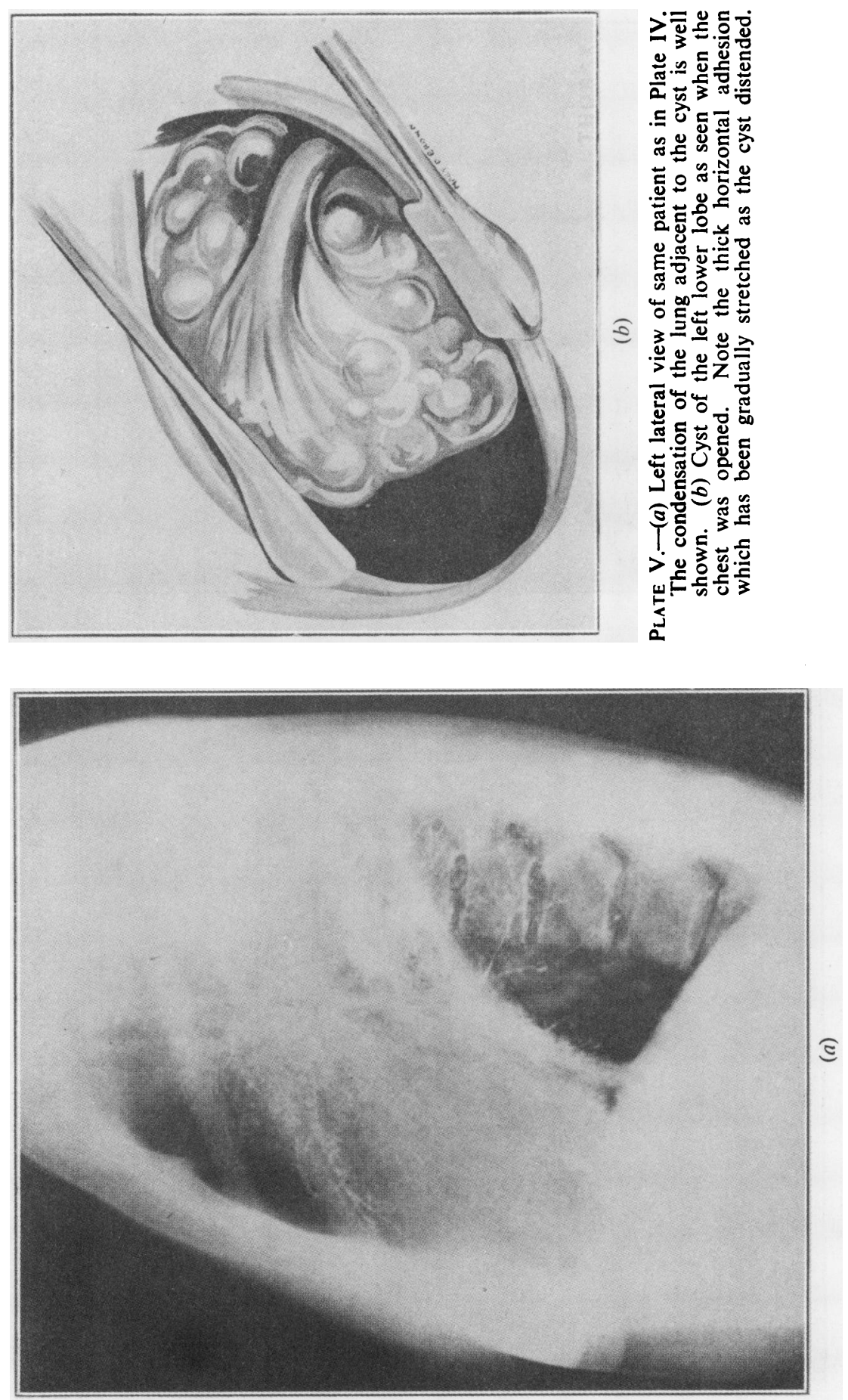

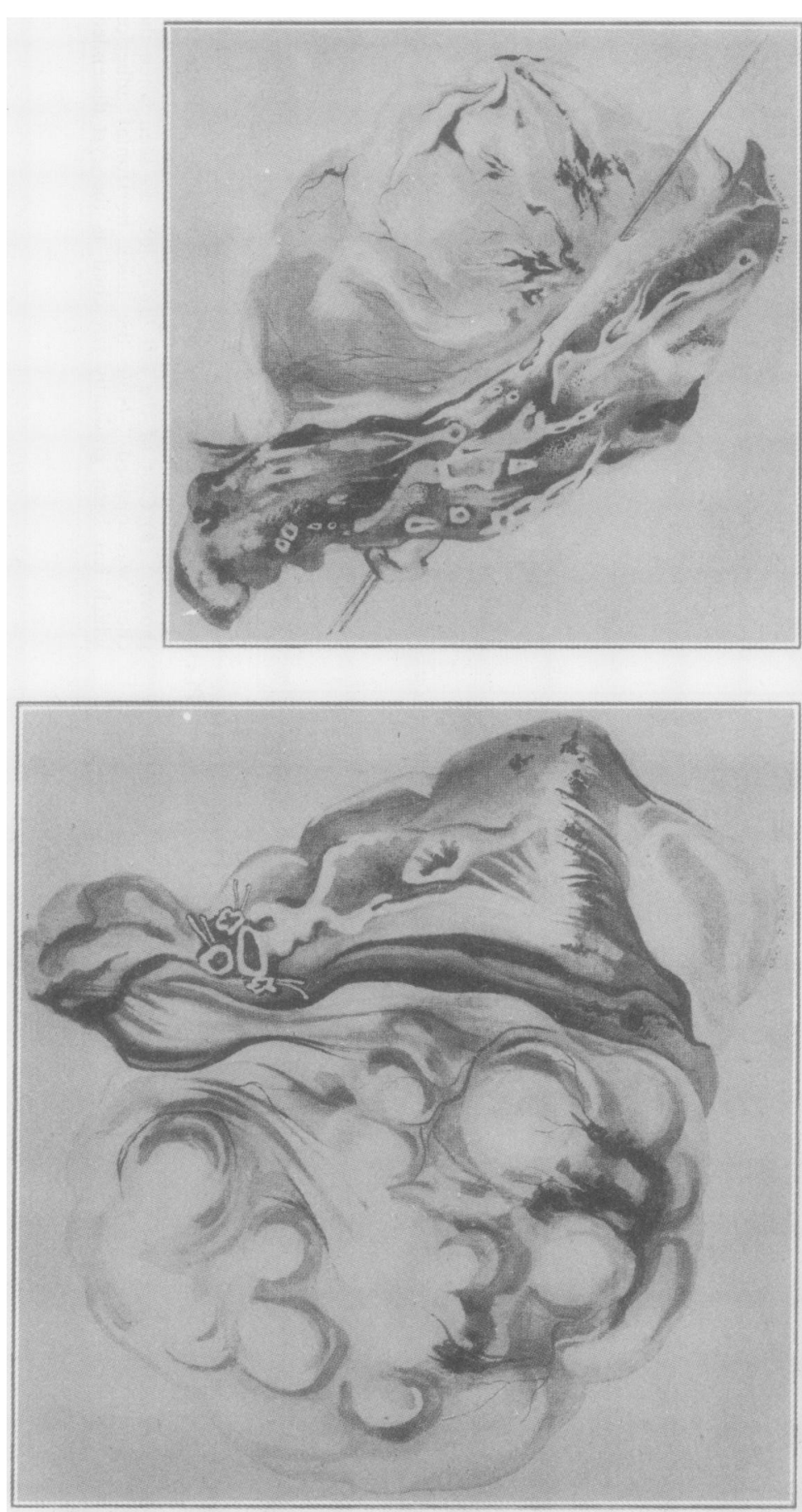

象器

政总

ㅇํㅇํํ

象

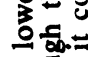

过

政

额

ब雨

웅현

E

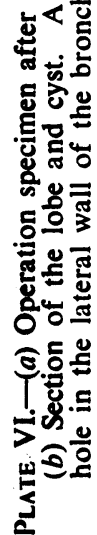




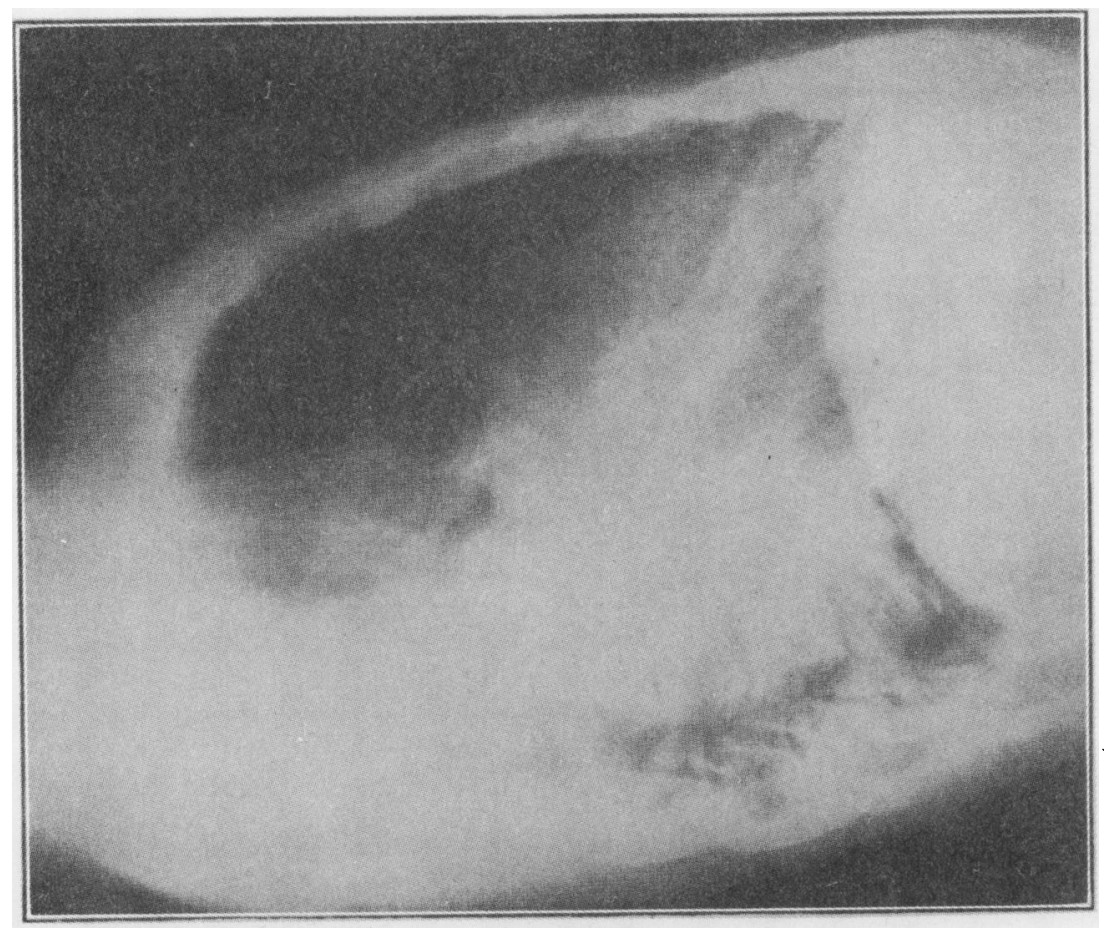

产
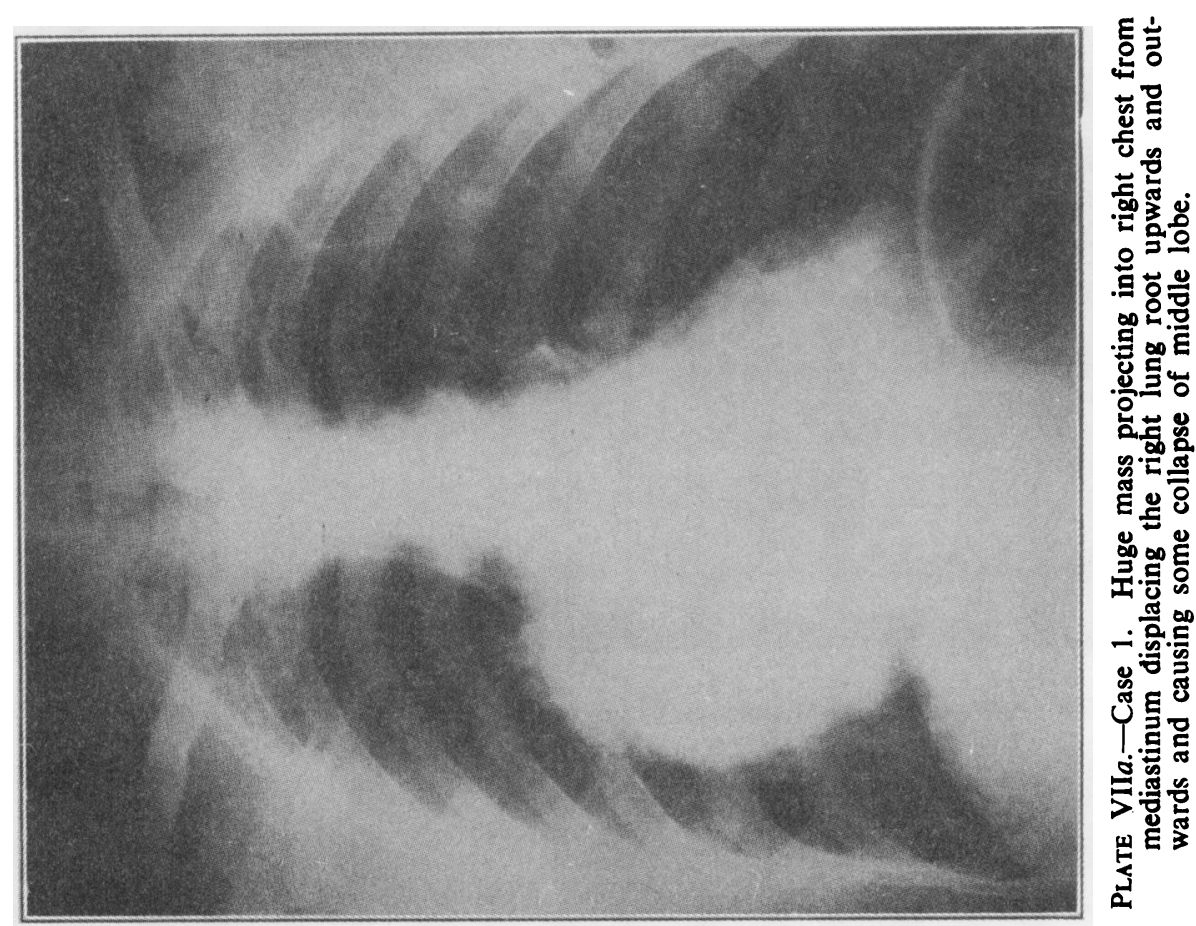

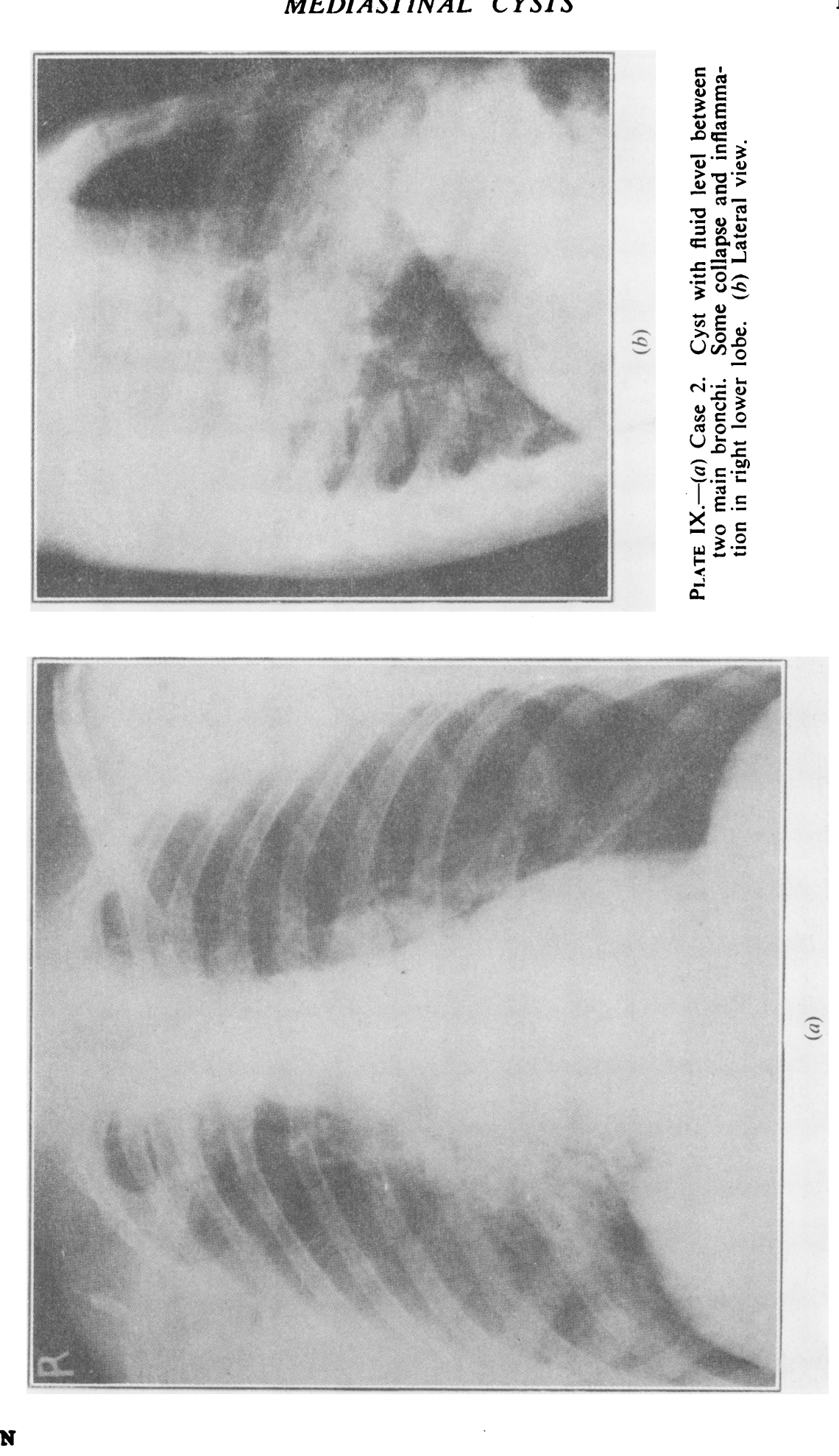


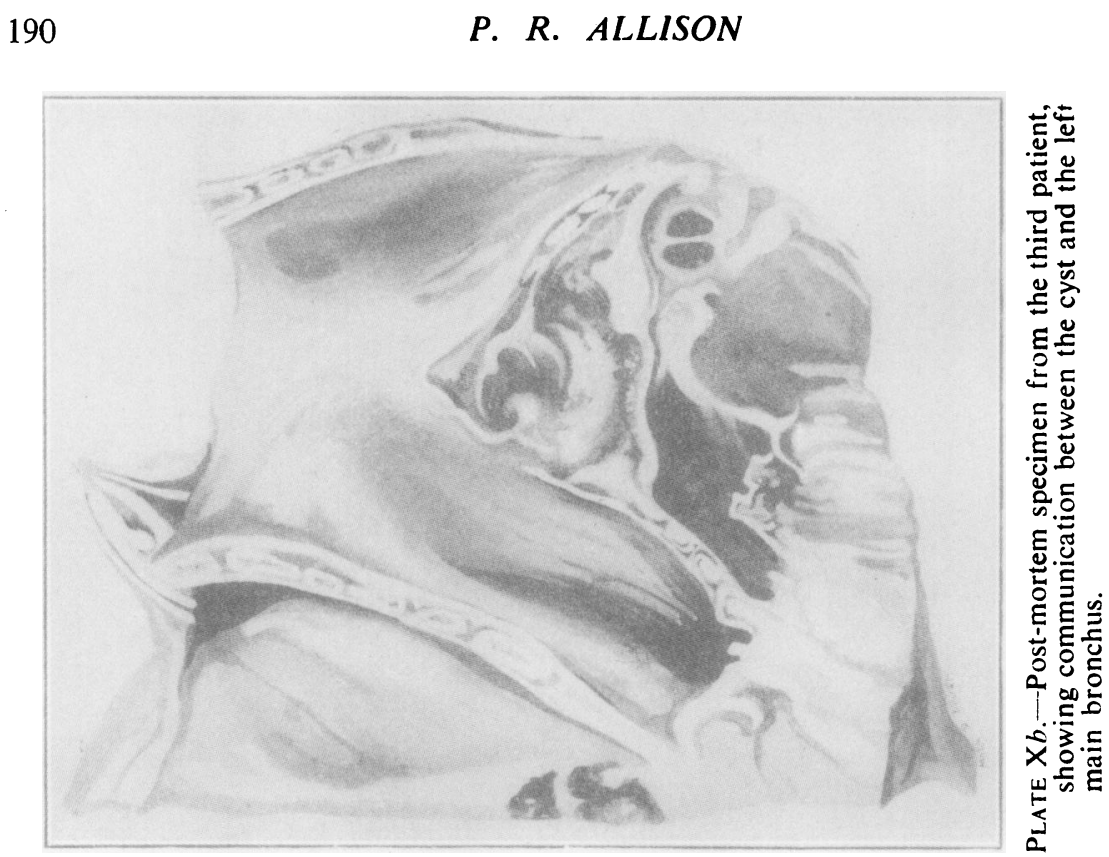

검

竞

믐

ह

$\overrightarrow{0}$

ज़

$N$

$\vec{\nabla}$

으

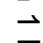

잉

$\frac{8}{3}$

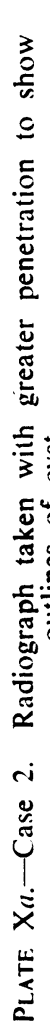

망

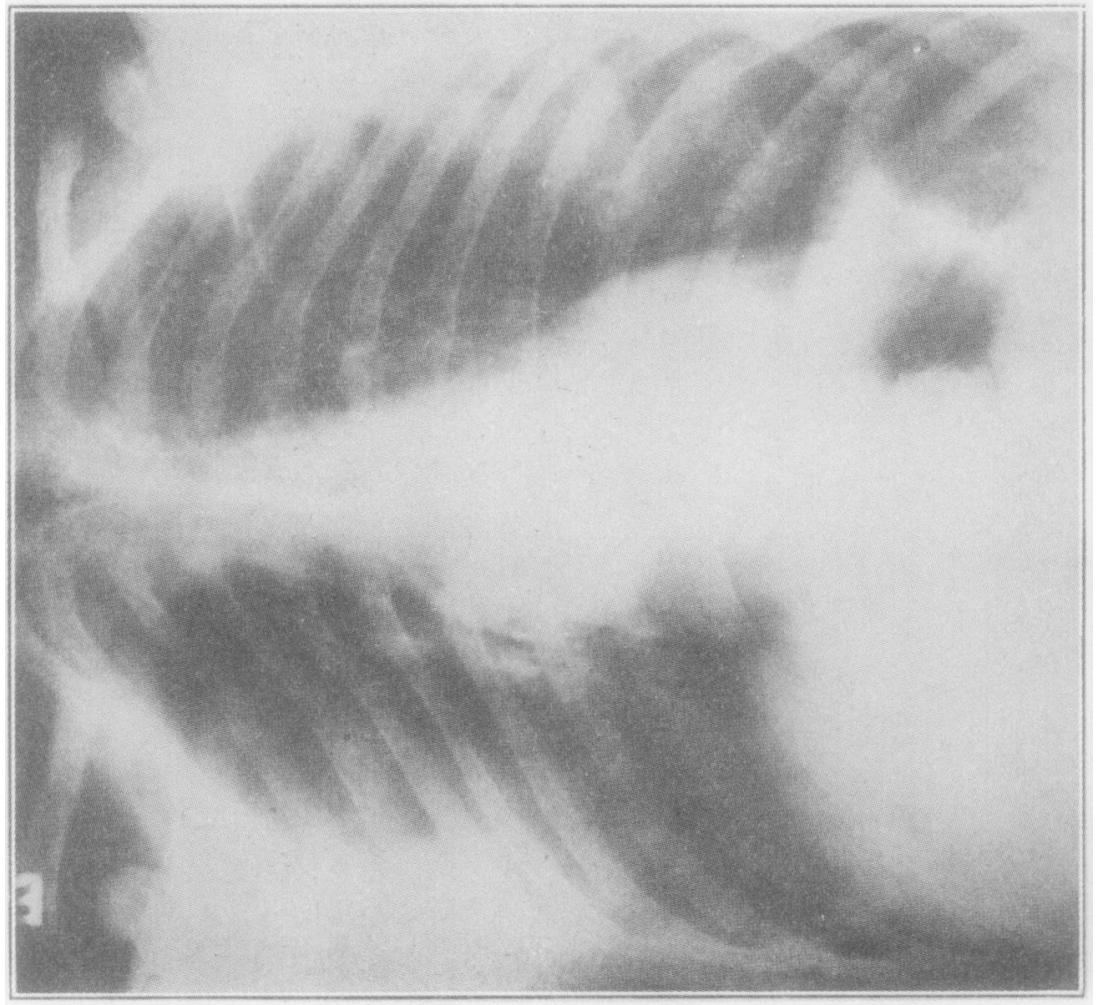

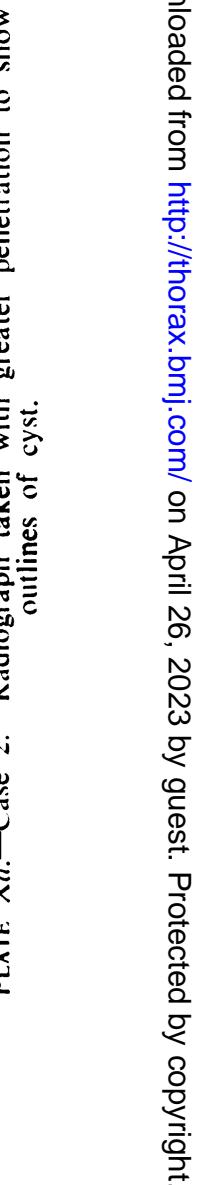



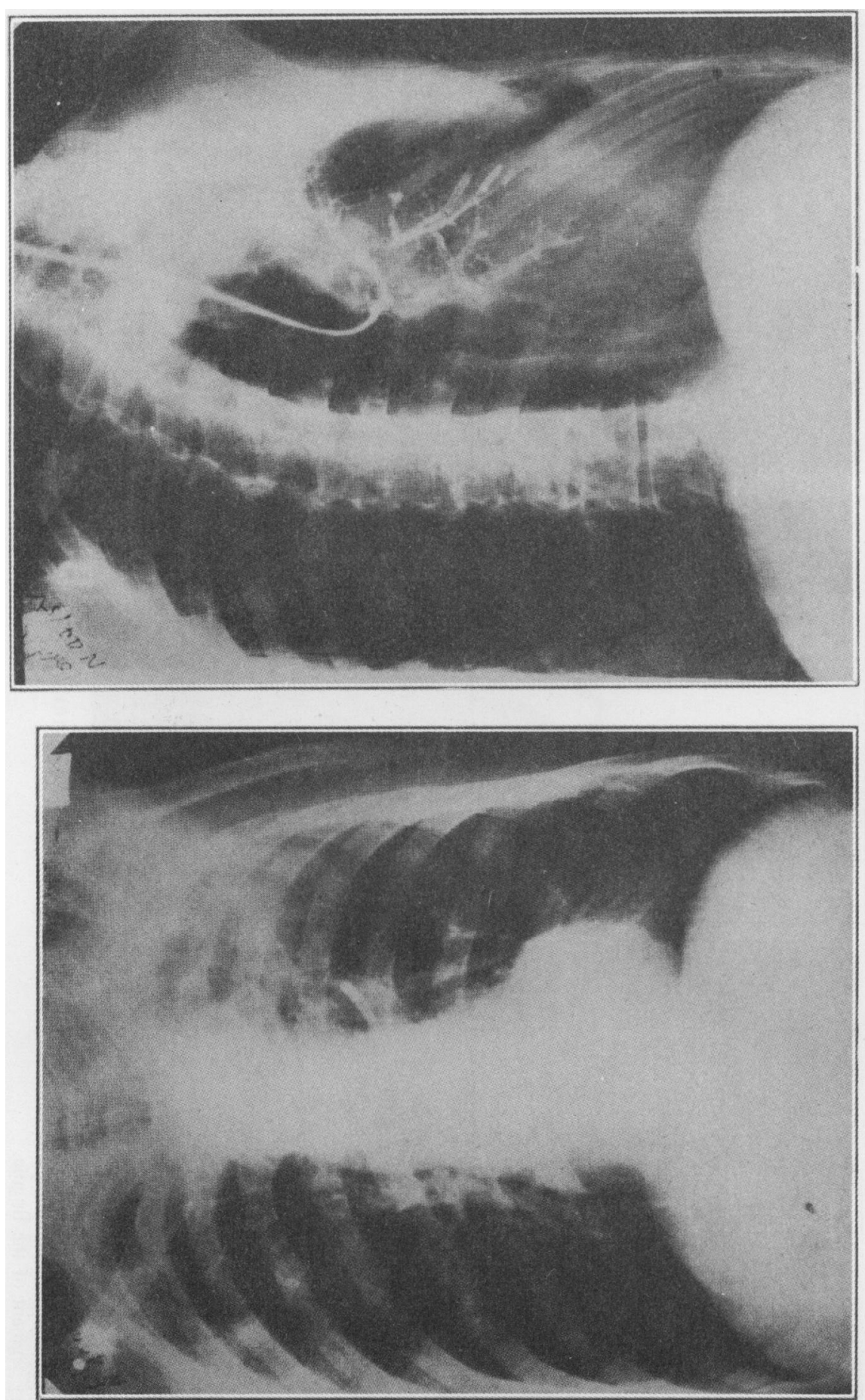

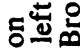

บ

羊舟

客象.

E $\dot{0}$

원른

co인

동잉

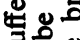

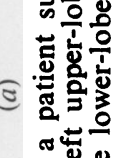

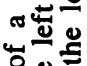

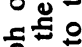

동.

․․․

응

串

콘홍

立

$\times \overline{\mathrm{g}} \cdot \overline{\mathrm{\sigma}}$

茨 


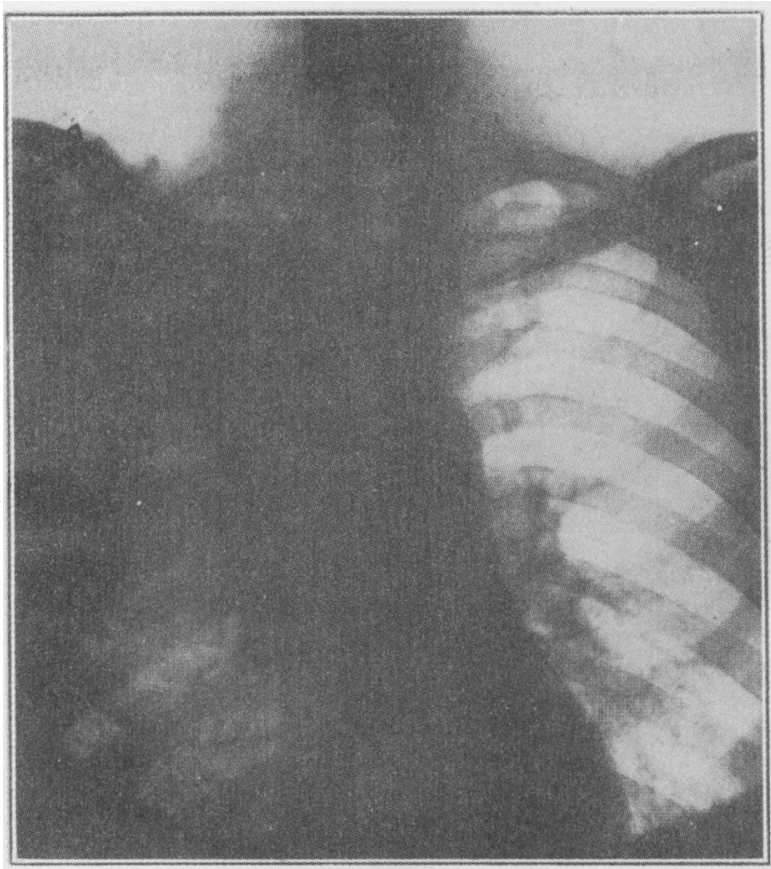

(a)

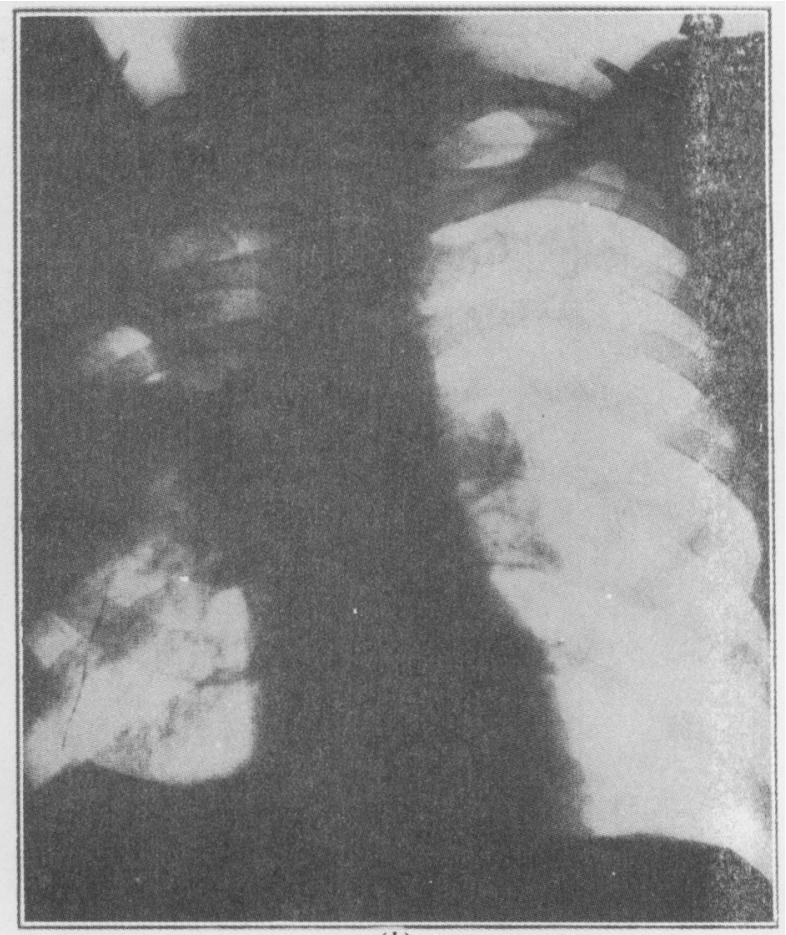

(b)

Plate XIII.-(a) Radiograph of a man aged 45, suffering from "pulmonary gangrene." The sputum was fetid and amounted to $450-500 \mathrm{ml}$. daily. He was profoundly toxic and had a high fever. (b) Radiograph of the same case, taken twelve days after the first, and after the sixth instillation of penicillin. (c) Same case, one month after the second radiograph. The patient has been followed up for more than one year and has had no recurrence of symptoms or signs. The remaining cavitation was, in fact, due to an emphysematous bulla which disappeared in the following weeks. Thus, " restitution ad integrum " was obtained within six weeks.

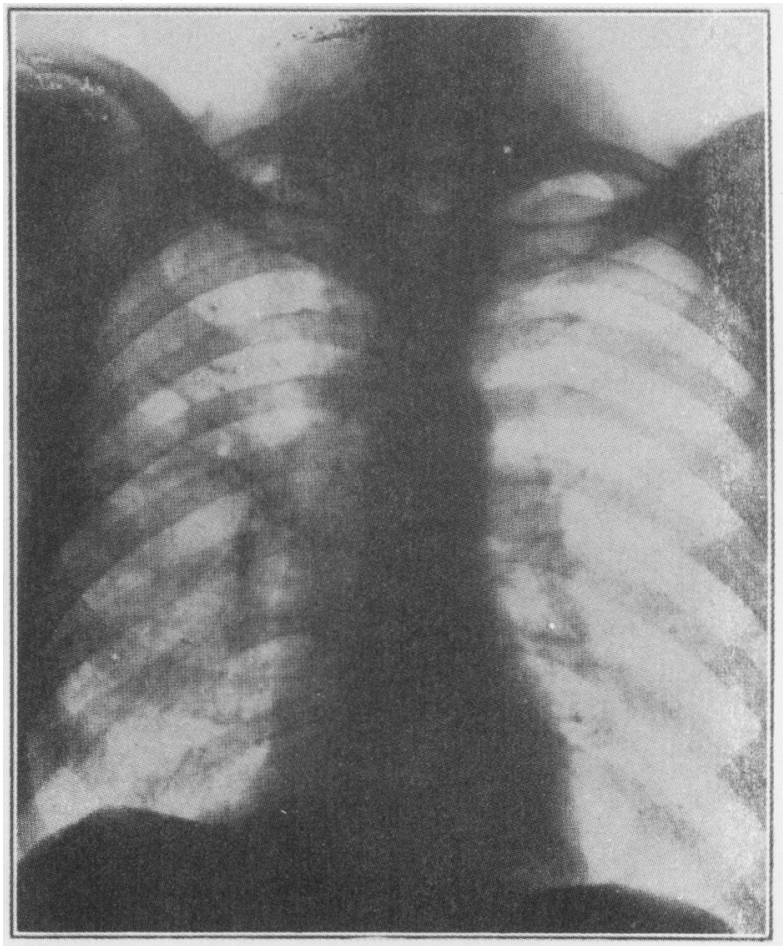

(c) 


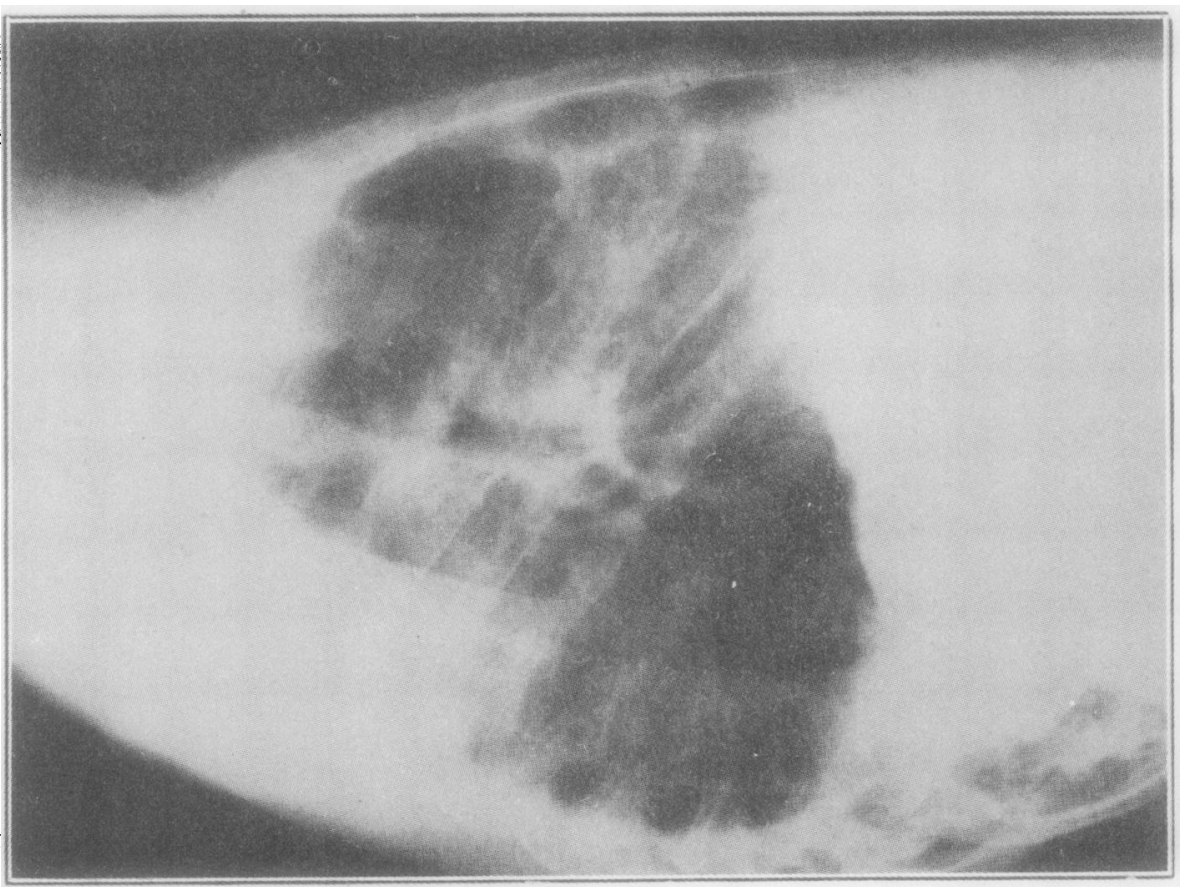




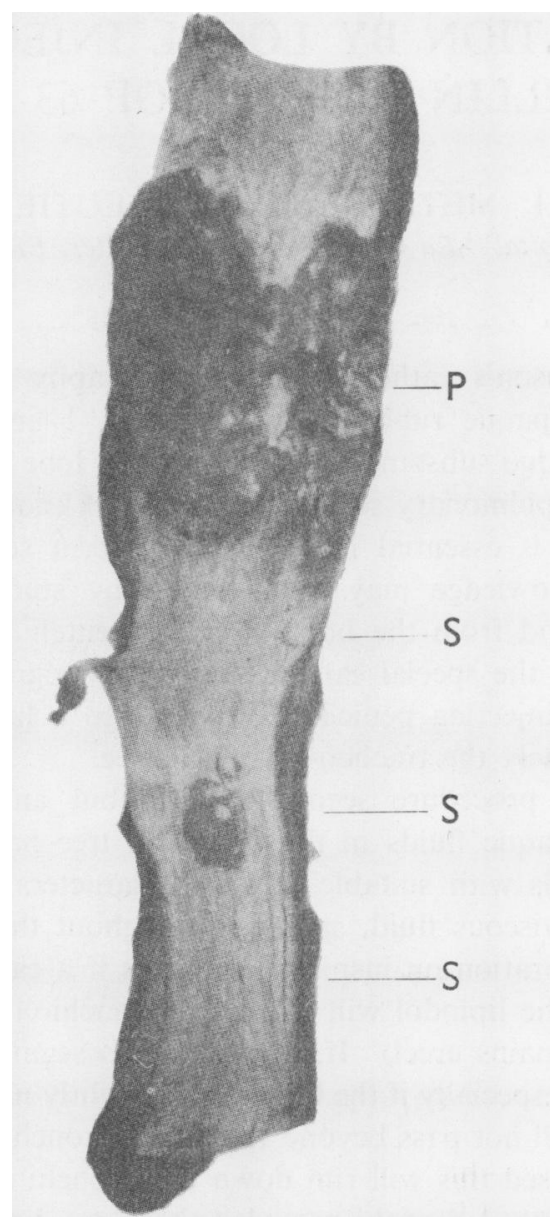

Plate XV.-Autopsy specimen of untreated oesophageal cancer, showing submucous permeation of growth. $\quad \mathbf{P}=$ primary growth ; $\mathrm{S}=$ secondary outcrops on mucosa. (From the Department of Pathology, St. Thomas's Hospital Medical School, by courtesy of Prof. W. G. Barnard.) 